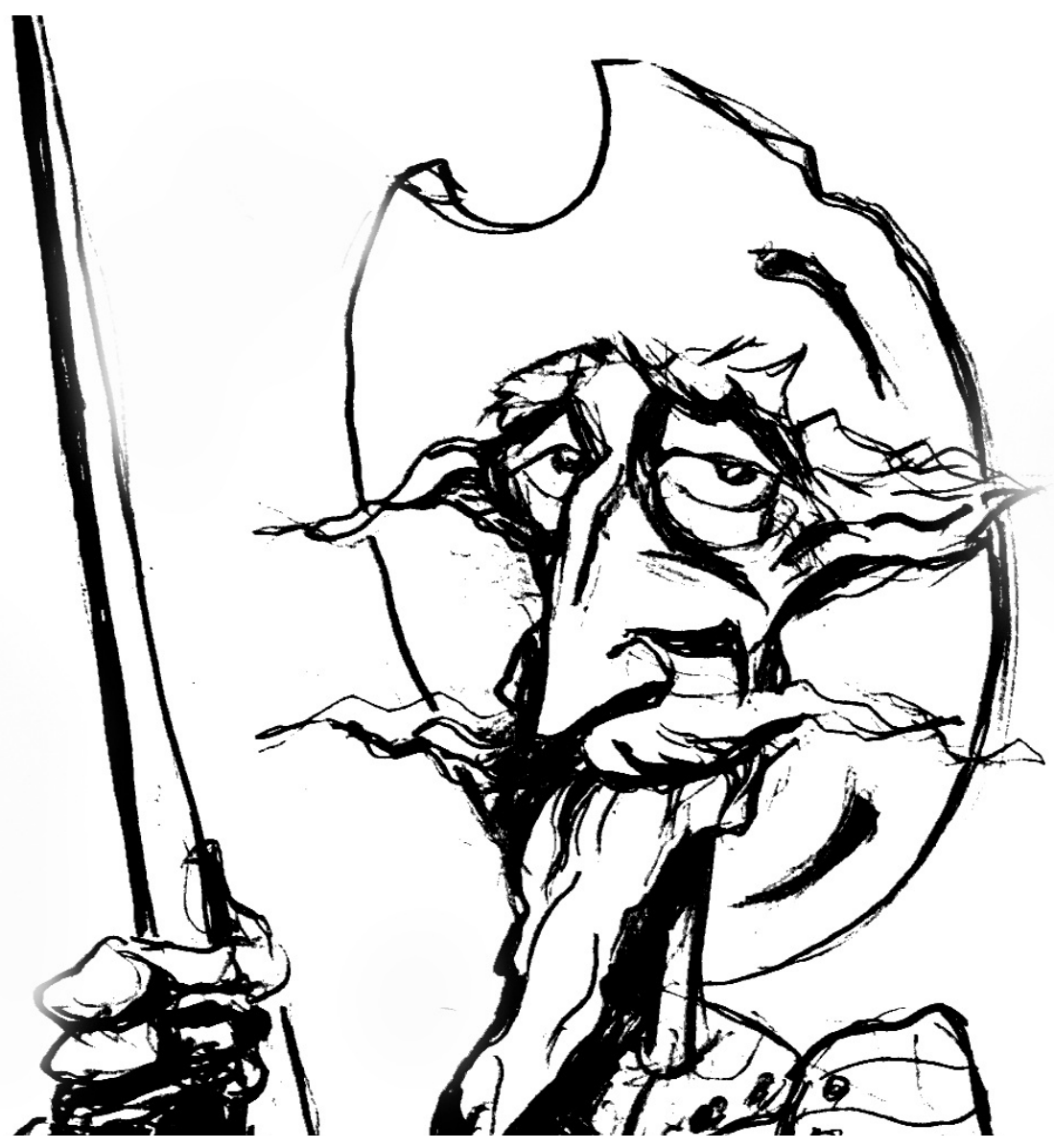

La producción de representaciones del pasado rosista en la trayectoria de Héctor P. Blomberg

[Leandro Nicolás Pankonin] 



\title{
La producción de representaciones del pasado rosista en la trayectoria de Héctor P. Blomberg*
}

\section{The Production of Representations of the Rosista Past in the Career of Héctor P. Blomberg}

\author{
LEANDRO NICOLÁS PANKONIN
}

\begin{abstract}
Resumen
El presente artículo tiene por objetivo presentar la obra de Héctor Pedro Blomberg dedicada a la época de Juan Manuel de Rosas, producida entre los años 1930 y 1940, y desarrollar una reflexión sobre las representaciones del pasado que proponen. Por otro lado, buscaremos indagar las diferencias y puntos de contacto entre estas formas de representar el pasado y las del emergente revisionismo, e hipotetizar sobre los impactos que estas distintas maneras de representar al pasado pueden haber tenido para la sociedad de aquel tiempo. Por último, intentaremos delinear algunas ideas sobre ciertos vaivenes en las interpretaciones rosistas sobre la obra de Blomberg, fundamentalmente para los años cincuentas y sesentas.
\end{abstract}

\section{Palabras clave}

Héctor P. Blomberg; Época de Rosas; Revisionismo Rosista; Representaciones del Pasado

\begin{abstract}
The present article aims to present the work of Héctor Pedro Blomberg dedicated to the period of Juan Manuel de Rosas, produced between the years 1930 and 1940, and to develop a reflection on the representations of the past that they propose. On the other hand, we will seek to investigate the differences and points of contact between these ways of representing the past and those of the emerging revisionism and hypothesize about the impacts that these different ways of representing the past may have had on the society of that time. Lastly, we will try to outline some ideas about certain ups and downs in the rosista interpretations of Blomberg's work, mainly for the fifties and sixties.
\end{abstract}

Key words

Héctor P. Blomberg; Time of Rosas; Rosista Revisionism; Representations of The Past

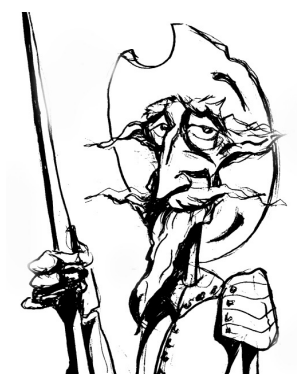

Recibido con pedido de publicación el 20 de agosto de 2020

Aceptado para su publicación el 10 de noviembre de 2020

Versión definitiva recibida el 3 de enero de 2021

Leandro Nicolás Pankonin, Universidad Nacional de General Sarmiento, Consejo Nacional de Investigaciones Científicas y Técnicas, Gral. Sarmiento, Argentina; e-mail: leandro_pankonin@yahoo.com.ar

* Agradezco los comentarios de los evaluadores de la revista

Esta obra se publica bajo licencia Creative Commons. Atribución-NoComercial-CompartirIgual 4.0 Internacional

Pankonin, Leandro Nicolás “La producción de representaciones del pasado rosista en la trayectoria de Héctor P. Blomberg", Prohistoria, Año XXIV, núm. 35, jun. 2021, pp. 107 - 134 


\section{Introducción}

El presente artículo tiene por objetivo considerar tres problemas. Por un lado, presentar la obra de Héctor Pedro Blomberg dedicada a la época de Juan Manuel de Rosas, producida entre los años 1930 y 1940, y desarrollar una reflexión sobre las representaciones del pasado que proponen. En segundo lugar indagar las diferencias y puntos de contacto entre estas formas de representar el pasado y las del emergente revisionismo, e hipotetizar sobre los impactos que estas distintas maneras de representar al pasado pueden haber tenido para la sociedad de aquel tiempo. Por último, intentaremos delinear algunas ideas sobre ciertos vaivenes en las interpretaciones rosistas sobre la obra de Blomberg, sobre todo las desarrolladas tras su muerte en 1955, etapa en la que el revisionismo -como interpretación historiográfica- y el rosismo como identidad política- ganaron gravitación y masividad durante la segunda parte del siglo XX. ${ }^{1}$

El 10 de abril de 1928 la revista semanal La mejor novela publicó una obra inédita de Héctor P. Blomberg titulada La sangre de las guitarras. Situada en los años en que Juan Manuel de Rosas gobernaba la Provincia de Buenos Aires, narraba una historia de amor entre Bernardina, una joven federala, y Marcelino Mitre, el más grande payador unitario de la época (Blomberg, 1928). Este fue un clivaje en la trayectoria del autor. Blomberg había nacido el 18 de marzo de 1889 en el barrio porteño de Monserrat. En la década de 1920 había logrado una importante inserción en medios periodísticos y literarios, y conseguido cierta visibilidad como cronista de los márgenes de la ciudad de Buenos Aires en las páginas del diario Crítica. ${ }^{2}$ Allí, en palabras de Sylvia Saítta, "incorpora como espectáculo nuevas zonas de representación que geográficamente se extienden desde los conventillos a los 'bajos fondos', pasando por la zona prostibularia, la cárcel o el manicomio" (Saítta, 2013: 192). La misma autora dirá en un trabajo sobre la producción de Blomberg dedicada a la época de Rosas, que su "fascinación por lo popular urbano" fue lo que definió su "perspectiva" (Saítta, 2019: 330).

\footnotetext{
${ }^{1}$ Usamos la denominación de rosismo dado que nos interesa abordarlo como una tradición política nacionalista que contuvo al revisionismo, de corte rosista, pero también lo desbordó. Es decir que hubo también, a lo largo del siglo XX, formas de rosismo que excedieron los debates estrictamente historiográficos, y consistieron en formas de reivindicación por medio de distintas campañas pro-repatriación y celebraciones públicas. Hubo también distintas confluencias con otras tradiciones políticas, y la concerniente a la relación con el peronismo durante la segunda mitad del siglo XX, es un debate siempre abierto. De esta manera enfatizamos el acento rosista ya que queremos subrayar que no entendemos a este y al revisionismo como elementos intercambiables, ni sinónimos.

2 A lo largo de su carrera Blomerg escribió artículos para los diarios La Razón, La Nación y Crítica; así como para las revistas Martín Fierro, El Hogar, Fray Mocho, Caras y Caretas, Leoplán, Aquí Está y Argentina.
} 
Para fines de esa década, con un prestigio ya ganado entre el público, pero también entre colegas de renombre, como Manuel Gálvez, Blomberg pareciera haberse lanzado a un nuevo programa literario. Así como se había convertido en cronista de los márgenes de la ciudad, comenzaría a indagar en los fenómenos de la cultura popular durante el período rosista. ${ }^{3}$ Para ello, se nutrió de obras de corte histórico y del trabajo en archivos, pero también de memorias orales. Así, se abocó a narrar aquello que sucedía en los carnavales, los mercados y las pulperías, entre payadores, mulatas y mazorqueros bajo los años de su gobierno. Tal como lo ha afirmado el propio Blomberg, no "le interesó Rosas por sí mismo, a pesar de su sombría y trágica grandeza personal, sino su época: los tipos, las costumbres, los cantos, los lugares sobre los cuales caía la roja sombra del Restaurador" (Blomberg, 1933: 7). Tal como lo afirmó Mónica Berman para el caso de Bajo la Santa Federación, lo tematizado es "su época, su entorno, pero no se lo construye [a Rosas] como personaje" (Berman, 2018:284). A eso nos referiremos con la época de Rosas. A una indagación enfocada en recorrer los andariveles de la vida social de aquel tiempo, con un acento puesto en fenómenos de la cultura popular, sin entrar necesariamente en deliberaciones sobre la figura de Rosas en sí misma.

Desde ese lugar de enunciación, asumió el desafío de construir una narrativa con características distintas a la que habían primado hasta entonces sobre aquella época. Y, tal como sucedió en el caso de La sangre de las guitarras, el propio devenir de los hechos, en consonancia con el éxito alcanzado por sus composiciones, lo llevarían a experimentar con otros soportes. ${ }^{4}$ Así, a la literatura, la intervención en la prensa, el teatro y la poesía, se sumaron la canción, el radioteatro y, más tarde, el cine.

Creemos que el prestigio ganado, la impronta de estética criollista en sus producciones - de buena acogida en la época- sumado a la construcción de un lenguaje con elementos comunes en distintos soportes, le permitieron a Blomberg tener un importante rol como constructor de imágenes de la época de Rosas para grandes públicos durante los años treinta y cuarenta.

Anthony D. Smith ha llamado la atención sobre el rol que memorias, valores, mitos, símbolos y tradiciones compartidas han tenido en la

\footnotetext{
${ }^{3}$ Cuando hablamos de cultura popular, nos referimos muy sucintamente a una definición relacional. En donde esta se constituye como tal, en tanto subalterna con respecto a aquello que consigue canon de hegemónico en un determinado momento de la relación de fuerzas de una sociedad. Ver: Hall, Stuart (1984). "Notas sobre la desconstrucción de lo popular", en: Raphael Samuel (ed.). Historia popular y teoría socialista. Barcelona: Crítica, pp. 93-110.

${ }^{4}$ Adaptado para el teatro por Vicente G. Retta, y estrenado en el Nacional de Buenos Aires en 1929, donde se mantuvo largo tiempo en cartel. Tres años después fue adaptada por Retta y Carlos Max Viale Paz para ser representada como opera en el Teatro Colón bajo la dirección de Ferrucccio Calusio y música de Constantino Vicente Gaito. En 1937 tendría su versión cinematográfica dirigida por Vicente G. Retta, y con guion de este último y Carlos Max Viale Paz.
} 
construcción y reactualización de las naciones y los nacionalismos, señalando que dichos elementos lejos de haber sido simplemente "inventados" desde el Estado moderno, tienen necesariamente cierta "resonancia" o "eco" previo, en algún sector de la población. Asimismo, Smith destacó el rol que los artistas populares han tenido para actualizar, crear, interpretar y reinterpretar las imágenes que hacen posible imaginar la nación para grandes públicos, agregando la atención sobre el hecho de que la popularidad que dichas imágenes puedan tener, depende -en parte- de las "resonancias" y "ecos" que pudieran generar en aquellos/as que las consuman (Smith, 2009: 30-33).

En un sentido semejante un joven Adolfo Prieto, prestó especial atención a las formas de circulación de estas obras y sus impactos en los grandes públicos. Lejos de afincarse en la dicotomía historiográfica que enfrentaba a revisionistas con liberales, afirmó -en 1959- que tanto la "permanencia del tema" para aquellos años como lo que garantizaba- entonces- su pervivencia, se podía explicar por la "compartida necesidad de revivir, míticamente, la existencia de un pasado trágico; y la intuición de que el proceso desencadenado por el episodio rosista tiene todavía abiertas sus instancias" (Prieto, 1959: 41).

Volviendo a la obra de Blomberg, entendemos que sin necesidad de forzar ningún tipo de interpretación sino prestando atención a las ambivalencias propias de todo proceso de construcción de sentido, quizás sea posible ver también allí un canal capaz de ponerle imágenes a una época obturada por la figura del líder político, y los debates en torno de sí. Y al hacerlo, de manera entretenida e informada, al mismo tiempo que alejado de la necesidad de estructurar su obra con la centralidad puesta en acumular adjetivaciones descalificadoras - o vindicadoras- sobre la figura de Rosas, es probable que haya habilitado una mirilla novedosa por la cual acercarse a su época. El compositor Juan Carlos “Tata” Cedrón, nacido en 1939, afirmó refiriéndose concretamente a las letras de Blomberg sobre la época de Rosas, que sus "canciones populares te despertaban el interés por saber qué había pasado". ${ }^{5}$

Proponemos, a través de estos elementos, un abordaje que nos permita abonar a una interpretación atenta a la manera en que los grandes públicos pudieron haber construido ciertas representaciones sobre el pasado de la nación durante los años treinta y cuarenta, en especial sobre la época de Rosas, en el mismo momento en que su figura irrumpió con fuerza en la agenda pública. Buscamos dar cuenta de la proliferación de representaciones sobre ese pasado que se dieron en distintos ámbitos, en distintos soportes, y con distintas valoraciones en aquella época. Testimonian este interés las encuestas que Crítica

\footnotetext{
5 "El fue el primero en hablar de barcos y puertos", Pagina 12, 3 de noviembre de 2018. El comentario del "Tata" Cedrón refirió a la obra hecha de canciones compuestas a partir de letras de Blomberg, música de Enrique Maciel, y voz de Ignacio Corsini.
} 
impulsó a fines de 1927 y en 1934, buscando discutir la figura de Rosas. La revista Caras y Caretas ya había hecho lo propio en 1933. Una nota publicada en las páginas de El Diario a propósito de la polémica por la repatriación de los restos de Rosas a mediados de 1934 afirmó:

"El caso de Rosas es un verdadero "caso". Mientras se multiplican los libros sobre su actuación, libros que aun sin quererlo están haciendo a Rosas una justicia póstuma bastante distinta a la justicia histórica, mientras en la radio, en el teatro, en los festivales, las poesías y música populares, la figura del Héroe de la Expedición del Desierto, goza de una presencia y de una aureola extraordinaria (la épica del periodo rosista es aprovechada al $100 \times 100$ por todas esas formas del arte y del pseudo-arte) en el recinto amurallado de la historia oficial, de las efemérides oficiales y de la memoria oficial, se quiere echar sobre Rosas una capa de olvido, completamente inútil por otra parte, porque la figura de Rosa se sale a cada rato de su lejana tumba de Southampton y cubre con su sombra la memoria del país". 6

Entre los elementos a tener en cuenta para dimensionar este fenómeno, sin duda, debe contarse también la identificación de Rosas con Hipólito Yrigoyen, por parte de la oposición, para impugnarlo (Saítta, 2013: 243-244). Pero también existieron representaciones de Rosas como figura de poder fuerte a ser actualizada por una propuesta corporativa, como podría leerse en la obra de Ibarguren que abordaremos más adelante.

El historiador norteamericano Mathew Karush afirmó que el cine, la radio y la música que se produjeron en la Argentina entre los veinte y treinta enfrentaron una dura competencia con el jazz y el cine de Hollywood, lo cual condujo a los productores culturales locales "a competir a partir de ofrecer aquello que la cultura extranjera no podía dar: la autenticidad nacional" (2013: 19). Pero dicha autenticidad nacional no se construyó sobre elementos aleatorios. Karush llamó la atención sobre el hecho de que las elites locales, tal como había sucedido en el resto de América Latina, durante el siglo anterior habían adoptado muchos productos y prácticas culturales europeas, de modo tal que ofrecían elementos muy poco idiosincrásicos. De este modo, fueron las prácticas culturales de las clases populares- o bien el imaginario en torno a lo que esas prácticas representaban- las mejor ponderadas para ser rediseñadas como auténticamente argentinas (2013: 28).

\footnotetext{
6 "La sombra de Rosas", El Diario (Buenos Aires), 22 de junio de 1934, Fondo Recortes periodísticos de Emilio Ravignani, Instituto de Historia Argentina y Americana "Dr. Emilio Ravignani", Facultado de Filosofía y Letras (FFyL)-Universidad de Buenos Aires (UBA) /VARIOS. T. II. 17 de abril de 1934 a 22 de julio de 1935, p. 322.
} 
Aquí queremos remarcar que el rotundo éxito radiofónico de "La pulpera de Santa Lucia" en la voz de Ignacio Corsini en 1928; o el radioteatro Bajo la Santa Federación de 1934, fueron contemporáneos con la organización de la Junta Americana de Homenaje y Repatriación de los Restos del Brigadier General Don Juan Manuel de Rosas, y la publicación de La Argentina y el imperialismo británico del mismo año. En ese sentido, nos interesa retomar los aportes de Mijaíl Bajtín, quien llamó la atención, hace ya muchos años, sobre el hecho de que ninguna enunciación de un sentido se da de manera aislada, sino que siempre existe una carnadura histórica, al afirmar que "Los enunciados no son indiferentes uno a otro ni son autosuficientes, sino que 'saben' uno del otro y se reflejan mutuamente. Estos reflejos recíprocos son los que determinan el carácter del enunciado." Por eso, "cada enunciado está lleno de ecos y reflejos de otros enunciados con los cuales se relaciona por la comunidad de esfera de la comunicación discursiva. Todo enunciado debe ser analizado, desde un principio, como respuesta a los enunciados anteriores de una esfera dada (el discurso como respuesta es tratado aquí en un sentido muy amplio): los refuta, los confirma, los completa, se basa en ellos, los supone conocidos, los toma en cuenta de alguna manera" (Bajtín, 2002: 281).

En base a estas perspectivas, buscamos reflexionar sobre los mensajes que la sociedad argentina de las décadas del treinta y el cuarenta puede haber recibido de aquellos que produjeron distintos tipos de representaciones del pasado nacional, particularmente de Rosas y su época, dimensionando su simultaneidad.

A modo de cierre dejaremos planteada una indagación sobre los desplazamientos en la interpretación del rosismo sobre aquella producción. Para eso analizaremos distintas formas de acercarse a la obra de Blomberg. Todo lo cual se desarrolló de manera concomitante al proceso por el cual el rosismo también se lanzó tácitamente a la tarea de conquistar grandes públicos.

\section{La interpretación de la interpretación}

En este apartado buscaremos exponer, y discutir, someramente con algunas interpretaciones consolidadas sobre la historiografía revisionista. En ese sentido vale decir que, yendo a los acontecimientos históricos, buena parte de aquellos que habían confluido en la campaña por la repatriación de los restos de Rosas en 1934, dieron paso a dos importantes instituciones en la historia de la reivindicación política de su figura cuatro años más tarde. El Instituto de Investigaciones Históricas Juan Manuel de Rosas (de aquí en más IIHJMR), en la ciudad de Buenos Aires; y el Instituto de Estudios Federalistas, de la ciudad de Santa Fe. Mientras el primero llegaría a tener, con el paso de los años, una estructura con filiales a nivel nacional; el segundo cerraría sus puertas en 1943.

También en 1938 había cambiado su denominación la Junta de Historia y 
Numismática Americana, fundada por Bartolomé Mitre, para pasar a ser ahora - decreto presidencial de Agustín P. Justo mediante- la Junta Nacional de Historia. Un año más tarde, el IIHJMR comenzó a sacar su Revista, donde -hasta la década del sesenta- se desarrollaron buena parte de los argumentos y debates historiográficos del revisionismo rosista. ${ }^{7}$ En los años cuarenta el Instituto también había comenzado a publicar un Boletín que, con interrupciones, salió hasta principios de la década del setenta.

Estos son algunos de los hitos fundamentales sobre los cuales se cimentó el debate historiográfico en torno a Rosas. Muy particularmente en la historiografía revisionistas de corte rosista, en la Argentina de la primera mitad del siglo XX, y que habría de estabilizarlas de manera creciente con el correr del tiempo. Fue a partir de estos elementos que Diana Quattrocchi Woisson entendió a la irrupción de estas representaciones de Rosas, en dicha coyuntura, como un "verdadero instrumento de contrahistoria" (1995: 81). En consonancia con la anterior, el historiador alemán Michael Goebel, lo catalogó como la evocación central del "nacionalismo", en el marco de lo que consideró una matriz interpretativa "biculturalista" de la identidad nacional. Separada en dos tradiciones político-culturales: la "liberal" y la "nacionalista" (2013:287). A nuestro entender, ambos autores en sus trabajos procuraron elaborar una crítica sobre el arsenal revisionista, pero terminaron por hacer propios sus argumentos, asumiendo que la Argentina había tenido una historia "oficial", hasta que el revisionismo llegó a ponerla en jaque, al afirmar que había "otra historia". En este sentido, coincidimos con el diagnostico de Alejandro Cattaruzza, cuando afirmó que:

"Mientras construía un adversario homogéneo, el revisionismo se daba unidad a sí mismo; así, la invención y difusión de la imagen que planteaba la existencia de una lucha entre la "historia oficial", un bloque sin fisuras, y sus impugnadores, otro conjunto que se pretendía uniforme, fue quizás el triunfo más importante del primer revisionismo" (2003: 156).

Haciendo caso a este último, nos interesa tomar la vía abierta por Darío Macor, quien prestó atención a la operación de "invención" de la década del treinta en el debate político intelectual de la Argentina sesentista. Así, buscó horadar la naturalización de la "década del treinta" como unidad de sentido, para dejar expuesto que "su invención" resultó ser:

"producto del debate político/ideológico que, provocado inicialmente por el quiebre del "consenso liberal" acelerado precisamente por la gran crisis con la que se inicia la década,

\footnotetext{
7 A modo de aclaración, vale recordar que la Revista del Instituto volvió a salir en los años noventa, y continúa en la actualidad.
} 
alcanzará su mayor densidad a partir de la caída de Perón y hasta bien entrada la década del setenta"(Macor, 1995: 2).

Dicho esto, entendemos que vale apoyarse en la operación señalada por Macor a fin de matizar el hecho de que las representaciones del revisionismo rosista hayan comprendido la totalidad de las formas de construir sentido sobre aquel pasado. Más bien creemos que dicha "invención" pudo haber aplastado otras imágenes de Rosas, y su época, que se encontraban en circulación en esos años, habiendo jerarquizado al revisionismo en una lectura hecha al calor de los años sesenta. En ese sentido, nos concentraremos a continuación en caracterizar cuáles entendemos que fueron concretamente los tópicos centrales con los cuales el revisionismo rosista representó a la figura de Rosas en los años treinta. Para pasar luego a analizar la obra de Blomerg dedicada a explorar aquellos años.

\section{Rosas y sus representaciones en la historiografía revisionista}

Dada la discusión que presentamos en el punto anterior con respecto a las representaciones de Rosas producidas desde el revisionismo rosista, nos centraremos aquí en tal cuestión. Tal como lo han resaltado Raúl Fradkin y Jorge Gelman vale subrayar que los libros más importantes dedicados a su figura, y su gobierno, "nos dicen hoy en día mucho más acerca del clima de ideas y las controversias políticas y culturales imperantes cuando fueron escritos que de la historia propia de Rosas e, incluso, de su época" (Fradkin y Gelman, 2016: 11). A continuación intentaremos desentrañar cuáles fueron aquellos nudos sobre los que se cimentaron las representaciones del rosismo reivindicativo durante la primera mitad del siglo XX.

Entre 1881 y 1883, Adolfo Saldías publicó su Historia de Rosas rebautizada Historia de la Confederación en 1888, en la que es reconocida como la primera obra de peso que intentó discutir las formas en que Rosas había sido representado hasta ese momento. Diez años más tarde se publicó La época de Rosas de Ernesto Quesada, hijo de Vicente Quesada. Fernando Devoto y Nora Pagano han aludido al criterio que pondera en sendas obras algún nivel de filiación con la tradición revisionista "ya que en ellas aparece con claridad y de manera suficientemente sistemática y aun erudita una reivindicación de la figura de Rosas y su época que eran el mayor lugar de memoria negativa del pensamiento argentino post-Caseros" (2009: 203). En el mismo sentido Alejandro Cattaruzza afirmó que estas dos obras tuvieron un carácter excepcional, para esta época, por su voluntad de construir un relato "verídico" (según los estándares científicos de la época) sobre dicho proceso histórico sin tintes marcadamente ideológicos ni morales (2007: 162-163).

Si bien las obras de Saldías y Quesada no fueron las únicas que tuvieron algún nivel de digresión con el relato hegemónico en torno a Rosas y su época, 
hubo que esperar hasta fines de los años veinte para que esta discusión tomara una densidad capaz de poner en juego las representaciones hegemónicas sobre dicho proceso histórico, y al mismo tiempo interpelar a distintos sectores de la sociedad. En ese sentido, procuraremos trazar aquí algunos nodos centrales con las que se construyó la representación de aquella figura en clave reivindicativa.

Para empezar, diremos algo sobre la cuestión criollista. Durante los años treinta la pampa se presentó, con renovado vigor, como un territorio desde el cual pensar la cuestión nacional desde ámbitos artísticos, políticos e intelectuales. Allí el arquetipo del gaucho ocupó un lugar central. Esa forma de imaginar la nación no era una novedad. Existía detrás de sí una heterogénea tradición estética y de pensamiento. A fines de los años sesenta, en un trabajo señero sobre la historia del nacionalismo argentino, Marysa Navarro Gerassi, ponderó -a la hora de explicar las razones de la emergencia de la figura de Rosas en los albores del siglo XX- que a la par de "la revolución académica" que representó la irrupción de una literatura renovada sobre el tema en aquella época, surgió también "un nuevo interés poético por la 'barbarie"” (1968: 132). En relación con este planteo, y a la saga de los esfuerzos que durante las últimas décadas se han hecho con ánimo de construir una mirada de mayor complejidad sobre las formas de usar el pasado, y prestando especial atención a lo sucedido durante la primera mitad del siglo XX, queremos retomar aquí un planteo de Alejandro Cattaruzza, quien remarcó que:

“durante el período de entreguerras podía verse la lenta consolidación de otro centro posible para la tradición argentina. Hasta los centenarios, Mayo aparecía en soledad; [...] funcionaba simbólicamente como episodio fundacional de la tradición política nacional, aquella que era específicamente argentina. Aquel otro centro posible de la argentinidad se rastreaba en producciones culturales rurales previas, más antiguas y primordiales, asociadas sin más precisión a un tipo social y ubicadas temporalmente en la colonia. Tanto una como otra argumentación poseían flancos visibles y eran, en un sentido, invenciones [...]. En principio, [...] todas ellas remiten al pasado; [y] su eficacia en la creación de sentido común no depende de su respaldo empírico o de su rigor científico, sino, una vez más, de condiciones político-culturales presentes, que impactan en su circulación y recepción. Por otra parte [...], en muchas intervenciones de intelectuales, a la hora de la acción estatal, en particular la escolar, y de los productos de la cultura de masas, ambas aparecían mezcladas y articuladas, sin mayor tensión. La nación de Mayo se cruzó allí con la nación del gaucho, figura ya admitida por el Estado en la segunda mitad 
de los años treinta, mucho tiempo después de que ello ocurriera entre los sectores populares..." (Cattaruzza, 2017: 73-74).

En consonancia con lo anterior, vale subrayar que la interpretación criollista del fenómeno rosista, no fue para nada exclusiva del revisionismo. Sino que también, y como lo veremos más adelante, hubo quienes abordaron al fenómeno histórico de Rosas y su época por esta vía, pero con un fuerte acento en lo estético. Tal como fue el caso de de Blomberg.

Volviendo sobre la producción de representaciones sobre este tópico, vale remarcar que la centralidad allí estuvo puesta en lo concerniente a la búsqueda de un mito nacional alternativo $-\mathrm{O}$ bien complementario- a la tradición de mayo. En esa lógica, si los revolucionarios de la primera junta de gobierno arrastraban inspiraciones foráneas, el gauchaje "tierra adentro" tenía una raíz vernácula, una fuerza telúrica por mostrar. Gálvez afirmó en su biografía de Rosas del año 1940, que la "Revolución nació oligárquica y aristocrática" a lo que contrapuso "la democracia" que "estaba en el campo, pues la plebe de la ciudad era servil en 1810. El gran demócrata era el gaucho, el hombre que amaba su libertad y respetaba la de los otros" (2007: 20). Rosas, en tanto hombre de las pampas que supo expresar las voluntades e intereses de la Argentina criolla, reunía todas las condiciones para ser expresión de ello. En ese sentido, Ibarguren construyó en Juan Manuel de Rosas. Su vida, su drama, su tiempo un contrapunto entre las incursiones del joven Juan Manuel de Rosas al territorio pampeano y su relación con su abuelo, León Ortiz de Rosas, en aquellos lares:

"Historias crueles de venganzas y de cautiverios, salvaciones milagrosas recordadas por los paisanos, comentarios de don León sobre la vida y las costumbres de las tribus que conoció bien en su aventura guerrera del Río Negro, familiarizaron a Juan Manuel con los barbaros pampas. Con frecuencia llegaban indios "amigos" hasta las poblaciones, traían cueros, plumas, quillangos, pieles de tigre, de guanaco y de zorro para trocar por tabaco, yerba, aguardiente, y abalorios que don León tenía siempre acopiados para el caso. Acampaban cerca, por temporadas, bajo toldos de cuero, se emborrachaban y hartábanse de carne de yegua, que la comían sanguinolenta y cruda. Juan Manuel mezclábase con los indígenas en la toldería, como buen camarada, y pudo bien pronto comprender su psicología y hablar su lengua" (Ibarguren, 1997: 19).

La composición de imágenes que ese libro llevó en su primera portada y sostuvo al menos hasta la quinta edición (definitiva) de 1935 bajo la editorial "La Facultad", tuvo por figura central al "Retrato de Juan Manuel de Rosas" pintado por el francés Raymond Auguste Quinsac Monvoisin en 1842. Una 
particularidad de dicha pintura es el poncho pampa que llevaba puesto Rosas. ${ }^{8}$ La representación de su figura en tanto gaucho, o bien vinculado con el mundo agrario, sirvieron para reforzarlo como punto de referencia local, capaz de sentar un antagonismo con las ideas liberales que venían de Europa y se ligaban con la vida en la ciudad.

En segundo término, es de resaltar la relación de tensión que la figura de Rosas acuñó con las ideas liberales. No solo en el tiempo mismo que gobernó la Provincia de Buenos Aires, sino a través de sus representaciones posteriores. En ese sentido cabe aclarar que dicha tensión se ha alojado sobre elementos distintos dependiendo de quien venga y en qué contexto haya sido construida. Vale recordar que Dardo Corvalán de Mendilaharzu reivindicó a Rosas como garante de lo conseguido en mayo (1929: 181-182). Pero, continuando con lo anterior, es posible identificar al menos tres entradas posibles al problema. El primero, en sintonía con lo afirmado anteriormente, es que Rosas representó el desafío de concebir un orden político con características propias, por oposición a importar uno foráneo. Otra entrada a esta cuestión, fue a través de la premisa de que no existía relación lineal entre el ideario liberal y la idea misma de democracia. Más aún, Rosas podría haber encarnado formas democráticas de gobierno disimiles con la democracia liberal. De esto se desprendió una doble derivación posible. Aquella que apeló al rol de un gobierno fuerte, y otra que otorgó una centralidad a la relación entre las masas y dicho liderazgo. Dependiendo del lugar de enunciación, ambos componentes pueden haber construido una unidad de sentido, o bien dos vertientes de interpretación distintas, e incluso contrapuestas.

Carlos Ibarguren llevó sus argumentos al punto de denominar al proceso rosista como una "dictadura trascendental" a la cual explicó como nacida de las propias condiciones sociales de "anarquía" generados por la revolución de mayo. Más aun, en sus términos la "dictadura no fue tan solo de un hombre, sino de un poderosísimo partido popular, y dentro de éste de la plebe urbana y rural que constituía su masa" (Ibarguren, 1997: 211). Por su parte, Julio Irazusta, atendió al problema de cómo concebir un orden político con características propias, por oposición a importar uno foráneo, y afirmó que el "calificativo de tiranía no es aceptable sino en el sentido que la palabra tenía históricamente en Grecia, donde el tirano era un caudillo popular" (Irazusta, 1935: 54). Por último,

\footnotetext{
${ }^{8}$ Roberto Amigo ha afirmado que durante la gobernación de Rosas, los retratos de su propia imagen fueron utilizados como una herramienta de propaganda política, y dichos cuadros tenían como elemento común la figuración de Rosas en tanto militar, o bien acompañado de la condecoración por la "campaña del desierto" de 1833. Por el contrario, aquellos "retratos de Rosas con poncho, vestimenta de campaña, solo eran utilizados por la prensa ilustrada de los exiliados en Montevideo (Muera Rosas! y El grito arjentino) para afirmar la diatriba de gaucho bárbaro". Comentario de la obra realizado por Roberto Amigo, disponible en: https://www.bellasartes.gob.ar/coleccion/obra/1913
} 
cabe dejar planteado cierto contrapunto construido en torno a Rosas y la cuestión católica, con una filiación a la reivindicación hispanista.

En tercer término, vale subrayar el modo en que la figura de Rosas pivoteó con el problema de la soberanía y del imperialismo en dirección a la construcción de un imaginario nacional. Aquí vale resaltar la dimensión central otorgada al problema de la unidad nacional construida, en buena medida, bajo la premisa de la defensa de la soberanía frente al asedio de las potencias imperiales. Un trabajo señero para estos problemas fue, sin duda, La Argentina y el imperialismo británico de los hermanos Julio y Rodolfo Irazusta, publicado en 1934. Cuestión que también fue tratada en Política británica en el Río de la Plata de Raúl Scalabrini Ortiz, publicado en 1940. Gálvez, por su parte, le puso atención a la celebración del patriotismo durante el gobierno de Rosas- elemento al que también le prestó atención Corvalán- como al problema de la injerencia extrajera propiciada y apoyada por sectores locales (Corvalán de Mendilaharsu 1929: 89, 188, 229 y 245; Gálvez, 2007: 384, 390 y 431). Otro trabajo gravitante de aquellos años, donde esta cuestión -con eje central en los vaivenes de la soberanía nacional- antes, durante y después de Rosas se abordó, fue Defensa y perdida de nuestra independencia económica de José María Rosa publicado en de 1943.

\section{Las representaciones de la época de Rosas en la cultura masiva de los años treinta: un estado de la discusión}

Vale remarcar, para empezar este apartado, que Blomberg no ha sido el único en explorar la época de Rosas desde la cultura masiva de los años treinta. Sino aquel en quien hemos concentrado nuestro análisis, dado lo prolífico y exitoso de su obra, así como también su peculiar vía de entrada al tema: lo popular. En ese sentido existen una serie de trabajos que han prestado especial atención a la producción de Blomberg, o bien de él junto a otros artistas. Alejandro Cattaruzza prestó atención a su producción en aquellos años. Muy especialmente al cumulo de composiciones que desarrollaron junto con Enrique Maciel. $\mathrm{Y}$ en ese sentido afirmó que "lo tornaron un momento histórico frecuentado, pero no inclinaron decisivamente la opinión a su favor" (Cattaruzza, 2007: 169).

Eduardo Romano, a propósito de los efectos que Bajo la Santa Federación pudo haber tenido sobre la audiencia de su época, afirmó que Viale Paz y Blomberg "no reverenciaron el módulo liberal oficializado", pero tampoco adoptaron una "actitud 'revisionista'". Más bien permitieron a su vasta audiencia acceder a "una versión del rosismo suficientemente diversificada, más allá de ciertas concesiones, y muy didáctica". Esto se debió al empleo de documentos, así como también al uso de referencias precisas a hechos, circunstancias, instituciones y personajes de la época. Esto, sin dejar de nombrar 
el importante repertorio de cielitos, gatos y otras canciones -sobre todo de autoría de Blomberg-, en cuyas letras es posible advertir una "idéntica flexibilidad comprensiva". Es decir que, "si algunos exaltan los sufrimientos de los opositores al Restaurador", otras "brindan una simpática imagen de los partidarios de Rosas" (Romano, 1985: 64).

Mónica Berman, mucho más cerca en el tiempo, publicó una obra fundamental sobre la construcción del radioteatro como género radiofónico en la Argentina. Allí la autora retomó muchos de los postulados de Romano y le reconoció a Bajo la Santa Federación no solo un lugar central entre los hitos fundacionales del género, sino también el canon de excepcional. Lo cual justificó bajo, al menos, dos argumentos centrales. El primero, la rigurosa investigación histórica a partir de la cual se confeccionó el guión radioteatral. Lo cual condicionó no solo la dramaturgia, sino también a las intervenciones actorales, que devinieron en necesariamente realistas o naturalistas. Todo lo cual no fue en detrimento de generar un producto masivo. $\mathrm{Y}$ en segundo término, la trayectoria de los autores. Que desembarcaron en el novedoso lenguaje del radioteatro, con un prestigio ya ganado por su obra previa. En comparación con otros radioteatros del momento, "la trayectoria de sus agentes es singular, porque propone otro tipo de escritura, otro modo de actuación, interpela otro tipo de radioescuchas y recurre a la historia nacional para construir la temática de su ficción" (Berman, 2018: 291). El trabajo de Berman resulta además un antecedente de peso para esta investigación, dado que puso atención en la contemporaneidad de este radioteatro y la irrupción del revisionismo rosista. Así observó para la época un "doble movimiento", por el cual "la figura ficcional de Rosas y su época, insistente en distintas instancias de la cultura: folletines, música popular, teatro, radioteatro y la figura histórica, revisitada en el marco de las investigaciones académicas, que parecen haber ido por caminos diferentes." (Berman, 2018: 271)

Silvia Saítta, siguiendo con la saga de trabajos dedicados específicamente a los radioteatros, aportó a esta discusión en un sentido que coincide plenamente con las hipótesis de este trabajo. Afirmó que si en su producción previa Blomberg había sabido construir "una época, un sistema de personajes, un escenario urbano", es "en la radio donde ese universo se sonoriza, trasciende las fronteras de la ciudad y logra, a través de las voces, un alcance nacional". Más aún, esto se conjugó con, o bien pudo derivarse de, su propio perfil: "extremadamente popular y erudito a la vez, portaba un nombre propio ya conocido, una velocidad de escritura sorprendente $y$, sobre todo, un mundo ficcional que ya había pasado por varias transposiciones genéricas: la letra de tango, la pieza teatral, el relato popular" (Saítta, 2019: 331-332). Otro punto importante de su trabajo, y coincidente con este, fue su atención al "clima de ideas" de la época, lo cual llevó a la autora a afirmar que "los radioteatros históricos de Blomberg expresan, en sede popular, los temas que están 
atravesando la discusión historiográfica de los años treinta". Contribuyendo así a "la construcción de un imaginario histórico que desbordó los claustros académicos y los círculos especializados, y se consolidó después en las versiones históricas del cine en los años cuarenta (Saítta, 2019: 336-337).

Es necesario mencionar aquí también el trabajo de la historiadora inglesa Lauren Rea. Coincidimos con ella plenamente en la necesaria ponderación del fenómeno de consumo masivo que resultaron ser las producciones de Blomberg -esta autora prestó atención especialmente a los radioteatros, pero también se incluyeron allí las composiciones del cancionero federal-, sumado a una coincidente voluntad de reflexionar sobre dicho fenómeno en diálogo con las maneras en que el pasado fue representado en el propio contexto de su producción: los años treinta y cuarenta. Pero disentimos con su interpretación a nuestro entender- demasiado lineal y esencialista de la obra de Blomberg, al inscribirla en una saga literaria que tendría por antecedentes directos a Amaliade José Mármol- y las novelas de temática rosista de Eduardo Gutiérrez. Más aún, creemos que ni siquiera existe un trayecto lineal entre haberse reconocido como "anti-rosista" ${ }^{9}$ y encuadrarse dentro de los parámetros de la "historia oficial" o la "historia liberal", tomando los términos que la autora homologó en su trabajo (Rea, 2013). Si bien nuestra investigación asume la circulación de representaciones como un dato de la realidad, busca afincar en sus puntos de interacción y por lo tanto disiente con las miradas que diseccionan los ámbitos de la realidad como compartimentos estancos, entendemos que abordar este fenómeno con las categorías del debate historiográfico, sin mediación, resulta problemático. Incluso si en algún caso fuera posible identificar las representaciones a las que aquí atendemos bajo posiciones ubicables en la dicotomía que contrapuso a revisionistas y liberales, debemos dar lugar a las ambivalencias a la hora de reflexionar sobre los impactos que esos mensajes pueden haber tenido sobre dicha sociedad.

\section{La época de Rosas, según Blomberg}

Ahora bien, volviendo sobre la obra de Blomberg, procuraremos a continuación hacer un repaso por su producción, así como también llamar la atención sobre los desplazamientos de su obra a otros soportes. Este autor publicó en febrero de 1929, luego de La sangre de las guitarras, el libro El pastor de las estrellas por la editorial TOR. Allí reunió por primera vez una serie de poesías que aludían a la época de Rosas bajo el título "Las guitarras rojas". Una de ellas se titulaba "La pulpera de Santa Lucía". Dicho poema, luego de ser musicalizado por Enrique

\footnotetext{
${ }^{9}$ Así lo afirmó en una encuesta realizada por la revista Aquí Está entre fines de 1939 y principios de 1940. Ver: Blomberg, Héctor P. (30 de noviembre de 1939). “El martirio de los prisioneros del Quebracho (un drama en 1841)”, Aquí Está, Año IV, núm. 369, pp.6-7.
} 
Maciel, se convirtió en el vals que se hizo famoso en la voz de Ignacio Corsini. Este fue el hito de inicio del llamado "ciclo federal" de este cantor.

En 1930 el tango "La mazorquera de Monserrat" tuvo su versión homónima adaptada para el teatro por Carlos Schaefer Gallo. La misma se estrenó el día 25 de septiembre en el Teatro Cómico de Buenos Aires con la Compañía Alippi-Rugero-Otal como "Pieza de época" y tuvo su publicación en La Escena a principios del año siguiente (Schafer Gallo, 1931). Dos días después, el 27 de septiembre, se estrenó en el teatro Apolo La pulpera de Santa Lucía. La adaptación teatral era de Blomberg mismo y Carlos Max Viale Paz, y la interpretación correspondió a la compañía de los hermanos Cesar y Pepe Ratti. Esta obra también se publicó en la revista La Escena (Blomberg y Viale Paz, 1930: 3). Blomberg afirmó un año después que tanto La sangre de las guitarras, como estas dos últimas obras, "al ser teatralizadas y llevadas a la escena, alcanzaron centenares de representaciones" (Blomberg, 1932: 7).

A finales de ese mismo año este autor reunió en un solo libro titulado $L a$ pulpera de Santa Lucia y otras novelas históricas una serie de relatos cortos escritos sobre la temática hasta el momento. Allí se encargó de narrar, la historia de Dionisia Miranda- la pulpera de Santa Lucía-, la hija de un soldado federal que atendía "la pulpería del Restaurador" sobre la calle Larga de Barracas, en las inmediaciones de la parroquia de Santa Lucia durante el año 1840. En el mismo volumen reunió también a: "La mazorquera de Monserrat", donde relató la historia de Baltasara Pacheco. Una negra, y ferviente federala, que vendía cigarros de la fábrica de la centenaria Mariana Artigas en aquel barrio de Buenos Aires. También fue de la partida "La sangre de las guitarras".

En 1932 Blomberg publicó su tercera novela larga, y la primera sobre la época de Rosas, titulada La mulata del Restaurador. El crítico de libros Raúl P. Osorio, vaticinó en su lanzamiento que las "aventuras de la mulata Paulina serán en breve tan populares como las de la pulpera de Santa Lucía". ${ }^{10}$ Desde el prefacio del libro, Blomberg afirmó que el "interés creciente demostrado por el público argentino durante los últimos años hacia los episodios y los personajes de la tiranía de Rosas, me movió a escribir la presente novela" (Blomberg, 1932: 7).

Ese mismo año realizó, junto con Carlos Max Viale Paz, su adaptación al teatro, que fue estrenada en el Nacional el día 12 de junio por la compañía Pascual E. Carcavallo, con "canciones y bailes criollos de Enrique Maciel”, y bajo el aditamento de "escenas populares de la época de Rosas". La misma se publicó en la revista Bambalinas en agosto de ese año (Blomberg y Viale Paz, 1932). La crítica teatral del diario La Razón afirmó al respecto el día del estreno que, unos meses más tarde de la salida de la novela homónima "con gran éxito de venta", el "mismo éxito de público acaba de repetirse en forma más directa y

${ }^{10}$ Caras y Caretas no 1749,9 de abril de 1932, p. 46. 
más cercana para el autor, con "motivo de la versión teatral de dicha novela". Se caracterizó a la puesta como hecha de escenas "verdaderamente populares y de un gran colorido", que "han trasladado a las tablas mil y un detalles de aquella época sombría". En ese sentido la crónica remarcó un elemento importante de la obra, a saber el hecho de que "los autores ponen en juego un elemento pintoresco que no ha sido tratado casi nunca con verdadero cariño: el candombe". Para terminar, se subrayó que el público "aplaudió con entusiasmo". ${ }^{11}$ También esta vez la revista Caras y Caretas subrayó el éxito de la empresa al incluir esta obra dentro de una nota titulada "Éxitos teatrales de 1932". La mulata del Restaurador era una de las obras que había tenido la "rara virtud de congregar auditorios numerosos y renovados" en un "mal año para nuestro teatro" ${ }^{12}$ Blomberg afirmó a principios del año siguiente que dicha obra había alcanzado cerca de doscientas representaciones (Blomberg, 1933: 8).

En 1933 Blomberg reunió en un solo volumen una serie de relatos breves publicados previamente, sobre todo en revistas. El libro se tituló La cantora de la Merced y fue publicado por la editorial Anaconda. Ese mismo año se presentó en el teatro la obra de Blomberg y Viale Paz El niño Juancito Rosas. Pero el hecho destacado fue el radioteatro Bajo la Santa Federación, que comenzó a salir en junio de 1933 y gracias a su rotundo éxito, tuvo una segunda temporada durante el año siguiente.

En 1936 publicó Canciones históricas. Allí, como un paso más en la tarea performativa de este autor sobre su propia obra, eligió agregarle un año a la mayoría de las canciones compuestas hasta el momento, para referirse al momento en el cual transcurre la historia que la composición relata. La publicación contuvo casi cincuenta canciones, de las cuales veinte aproximadamente - tal como lo afirma Blomberg en el prólogo- habían sido musicalizadas por Maciel. No todas las composiciones allí fueron sobre temas federales, pero sí la enorme mayoría (Blomberg, 1936).

Hacia finales de la década la editorial Sopena publicó en un único volumen "La mulata del Restaurador", "La pulpera de Santa Lucía", "La guitarrera del cerrito", "La mazorquera de Monserrat", "La sangre de las guitarras" y "La leona de los llanos". Allí repitió, en las palabras preliminares, una operación presente en otros textos. Dio cuenta de la literatura escrita sobre la época de Rosas, de la que únicamente rescató a Amalia, y dio cuenta del modo en que él mismo había intentado trabajar al "describir tipos y escenas eminentemente populares, apartándome de la trillada ruta de los idilios unitarios y evitando los relatos de sangre tan caros a los folletinistas de antaño" (Blomberg, 1938: 6).

\footnotetext{
11 "Aplaudiose en El Nacional 'La mulata del Restaurador'”, La Razón s/f.

12“Éxitos teatrales de 1932", Caras y Caretas no 1.785, 17 de diciembre de 1932, p. 125
} 
Ese mismo año volvió a la temática naval y publicó el libro Cantos navales argentinos. Allí le dedicó también dos poemas a los años de la federación: "Las naves rojas de la federación" y "Canto a los héroes de Vuelta de Obligado (1845)". Este libro volvió a publicarse cuatro años más tarde por Sopena en un volumen junto $A$ la deriva -libro por el que había sido premiado en 1921-.

En sus próximos libros se mantuvo en la órbita de temas criollos, pero sin tener en el centro de la escena a los años de la Federación. Donde sí continuó desarrollando esta cuestión fue, por un lado, en la prensa periódica. Publicando notas fundamentalmente sobre los negros y negras, y sobre los carnavales en tiempos de Rosas, así como ciertas semblanzas sobre sus propias canciones. ${ }^{13} \mathrm{Y}$, por otro lado, en los radioteatros.

Entre los meses de julio y agosto de 1939 se emitió por radio Prieto Las rosas de Caseros, que contó con la joven actriz Eva Duarte como figura central de su elenco. No era la primera vez que trabajaban juntos, ni sería la última. Por el contrario habían tejido un importante vínculo laboral. Pero aquella historia que transcurría en los días posteriores al 3 de febrero de 1852, significó un salto muy importante en la carrera actoral de Evita (Maranghello, 2016: 223-225). Dos años después, en 1941, Blomberg llevó al radioteatro una versión propia de Juan Cuello escrito por Eduardo Gutiérrez en 1880.

Falleció el 3 de abril de 1955.

\section{Blomberg lector}

Intentaremos agregar aquí algunos elementos sobre el lugar de enunciación que entendemos que Blomberg buscó construir. Para eso buscaremos dar cuenta, por un lado, de aquellos autores con los cuales trabajó para crear sus representaciones; y aquellos de los cuales buscó demarcarse, aun reconociéndose como heredero. De esta manera intentaremos dar cuenta de que el modo en que Blomberg representó la época de Rosas puso el acento, tal como lo dijimos anteriormente, sobre todo en los fenómenos de la cultura popular: qué sucedía en los carnavales, los mercados y las pulperías, entre payadores, mulatas y mazorqueros.

Ahora bien, para empezar diremos algo sobre las tradiciones literarias con las cuales Blomberg trabajó, al mismo tiempo que se vio en la necesidad de demarcarse. En primer lugar, la llamada generación de 1837. David Viñas

\footnotetext{
${ }^{13}$ Héctor P. Blomberg, "Los negros de Buenos Aires", ¡Aquí Está!, Buenos Aires, 21 de abril de 1949, p. 18-19 y 23; Héctor P. Blomberg, "La negra y la mulata en la poesía americana", Suplemento Cultura-La Nación, Buenos Aires, 26 de mayo de 1940, p. 2; Héctor P. Blomberg, "Carnavales porteños del pasado", ¡Aquí Está!, Buenos Aires, 5 de febrero de 1948, pp. 8-9; Héctor P. Blomberg, "En 1840 la pulpera de Santa Lucía vivía en Barracas", ¡Aquí Está! núm. 452 año $\mathrm{V}, 16$ de septiembre de 1940, pp. 2-3
} 
afirmó, en un trabajo ya clásico de la crítica literaria local, que la literatura argentina es "la historia de la voluntad nacional", y en tal sentido "empieza con Rosas" (Viñas, 1982: 14). Siguiendo con esa hipótesis, habría sido la generación de 1837, los llamados románticos, quienes empujaron la creación de una narrativa vernácula, con ánimo de discutir y antagonizar con Rosas. Así, la hegemonía política liberal posterior a Caseros, y sus formas de construir imaginarios nacionales, se habría visto alimentada por obras nodales de esos autores: el Facundo de Domingo Faustino Sarmiento, El matadero de Esteban Echeverría, y Amalia de José Mármol, por nombrar solo sus expresiones más reconocidas.

Por otro lado, para fines del siglo XIX, y principios del XX, se desarrolló en nuestro país - pero sobre todo con epicentro a ambas orillas del Río de la Plata- una literatura criollista, que tuvo a los gauchos en el centro de su narrativa. $\mathrm{Y}$ que tal como vienen mostrando investigaciones recientes, puede afirmarse que fue un fenómeno sumamente significativo hasta, por lo menos, los años del primer peronismo (Adamovsky, 2019). Una característica central de su irrupción, fue el efecto de circulación y consumo masivo que tuvo sobre grandes públicos. Si bien pareciera no haber dudas en que su hito fundante radicó en la publicación, en 1872, del Martín Fierro de José Hernández; otro escritor, inscripto en esa estética, que sobresalió e incluso fue mucho más prolífico que el primero, fue Eduardo Gutiérrez. Quien le dedicó largas páginas a denunciar los "dramas del terror" durante la época de Rosas (Prieto, 2006).

Ambas tradiciones literarias: el romanticismo de la generación del 37, sobre todo en la figura de Mármol; y el criollismo de Eduardo Gutiérrez, generaron una importante influencia sobre la obra de Blomberg. Tanto es así, que este publicó, en 1927, una nota titulada "Las novelas de la tiranía de Rosas". Allí, buscó realizar un repaso por aquellas novelas que comenzaron a publicarse en Buenos Aires y España cinco años después de Caseros, y "merecen la calificación de tales". A las cuales catalogó como "novelas de odio y sangre" que "recogieron las leyendas del rencor unitario" y revivieron episodios de dicha época a veces "tergiversándolos torpemente". De entre todas ellas, para Blomberg, se destacaba una de gran talento: Amalia, de José Mármol. ${ }^{14}$

Un año después realizó una operación similar en una nota dedicada a Eduardo Gutiérrez. Allí afirmó que "Desde el nacimiento de Juan Manuel de Rosas, 1793, hasta la muerte del Chacho, 1870 [1863], la vida de las generaciones argentinas pasa por las innumerables páginas de sus romances, agitada, tumultuosa y ardiente, deformada muchas veces por su ardor imaginativo, pero real y humanísima", a lo que sentenció de inmediato que "el rio de sangre que

\footnotetext{
${ }^{14}$ Héctor P. Blomberg, "Las novelas de la tiranía de Rosas", Suplemento "Letras y artes" La Nación, 10 de julio de 1927, p. 3.
} 
enrojece estos libros toscos y celebres es la falla más reprobable de Eduardo Gutiérrez". ${ }^{15}$ Esta argumentación se repetiría más de una vez en la presentación de sus futuras obras literarias sobre la época de Rosas para resaltar que, a pesar de ser "una fuente inagotable de sugerencias literarias" (Blomberg, 1933: 5), la enorme mayoría de lo dicho al respecto hasta el momento carecía de valor literario, o bien redundaba en la apelación permanente a la truculencia. Desde allí construyó su lugar de enunciación. En sus palabras:

“Desde 1929, año en que se publicó la novela y se estrenó $L a$ sangre de las guitarras, obra primigenia de mi serie "rosista", me dediqué a evocar a los hombres y mujeres del pueblo porteño. Los fui a buscar a las pulperías, los mercados, los cuarteles, el matadero, los suburbios hormigueantes, las parroquias rumorosas, y los he evocado con toda la vida posible en la serie, ya un poco larga, de mis romances y dramas de la tiranía breves casi todos ellos, pero, a los cuales traté de dar colorido y realidad" (Blomberg, 1933:7).

Tal como lo adelantamos en la introducción a este trabajo, nos permitimos hipotetizar que Blomberg pudo haberse propuesto trasladar la operación de cronista de los márgenes, no ya para la Buenos Aires de su tiempo, sino para la geografía urbana de la ciudad durante los años de la Federación. En este sentido es interesante traer a colación la propuesta desarrollada en el Cancionero Federal, de 1934, que él mismo prologó, recopiló y comentó. Una importante obra de relevamiento de fuentes que no habían sido exploradas aún en profundidad, y lo serían de manera creciente a partir de la publicación de este trabajo. Allí desarrolló una crítica a Ricardo Rojas, a quien le endilgó haberle quitado valor a "los versos en loor de Rosas" en el volumen Los proscritos de su obra Historia de la literatura argentina de 1922 y afirmó que "la lira rosista, o rosina, como se decía entonces, estuvo vibrando durante cerca de un cuarto de siglo", a lo que agregó:

“Yo, modesto aficionado a la evocación de las cosas de aquel tiempo, en el que solo he buscado los aspectos dramáticos, poéticos y pintorescos, he querido salvar la voluntaria laguna dejada por Ricardo Rojas en su monumental y preciosa obra. Por eso me pasé varios años escudriñando pacientemente las colecciones de diarios y periódicos, desde 1830 hasta 1852" (Blomberg, 1934: 8).

Blomberg rebatió el argumento de Rojas respecto al poco valor literario que este había encontrado en la poesía restauradora, y afirmó que:

\footnotetext{
${ }^{15}$ Héctor P. Blomberg, "El puñal de Eduardo Gutiérrez", en: Caras y Caretas no 1.529, Buenos Aires, 21 de enero de 1928, p. 136.
} 
"no todo era temor y servilismo en esta poesía "restauradora". Junto a los Madrigales a Manuelita, que ya hemos mencionado, encuéntranse nobles y hasta inspirados acentos: eran los poetas sinceros, los cantores auténticos de aquella Federación que estaba en el corazón de los argentinos" (Blomberg, 1934: 10).

En directa consonancia con lo que venimos planteando, se demarcó también de este -a quien admiraba explícitamente- por aquello que había omitido, y a Blomberg le interesaba especialmente: la poesía popular de aquel tiempo.

Será justamente aquella popularidad la que este autor reconstruirá en base al libro de Carlos Ibarguren Juan Manuel de Rosas: su vida, su tiempo, su drama, de 1930. Citando aquella biografía, retomó una afirmación expuesta anteriormente en este trabajo, para preguntarse: “Quién que tenga algún conocimiento de la famosa época, puede desconocer el hecho de que el partido federal era 'un fuerte y poderosísimo partido popular'? (Carlos Ibarguren, 'Juan Manuel de Rosas')" (Blomberg, 1934: 10-11). La obra de Ibarguren volverá a aparecer en cada una de las reposiciones de contexto que Blomberg construyó para introducir los capítulos de dicho trabajo (1934: 23 y 163).

Dicho esto, vale traer aquí otra marca en su producción, sobre aquellos autores de los que se reconoció a sí mismo subsidiario. En 1933, desde el prólogo de La cantora de la Merced afirmó:

“En 1907 el doctor José María Ramos Mejía dio a publicidad el trabajo más completo y profundo que se ha escrito sobre la grandiosa figura del Restaurador. Pero debían transcurrir veintitrés años hasta que el doctor Carlos Ibarguren -que años antes escribiera un bello libro sobre Manuelita Rosas, - diera a la estampa su “Don Juan Manuel de Rosas", iniciando con brillo y sabiduría, la biografía novelesca en las letras nacionales.

Las novelas sobre la tiranía aparecidas durante los últimos cinco años son abundantes. Sólo merece recordarse entre ellas las de Hugo Wast y la de Manuel Gálvez, plena de poesía y emoción. Las demás sólo son ensayos de escritores, indocumentados, a los cuales fascinó la época y se apresuraron a evocarla sin contar con los elementos indispensables para ellos" (Blomberg, 1933: 6).

No resulta un detalle menor que en la amplia y heterogénea gama de representaciones del pasado rosista, que se encontraban en circulación para la época en que Blomberg produjo su obra, este haya ponderado especialmente no solo lo escrito por Ibarguren y Gálvez, sino también lo de Hugo Wast o Gustavo A. Martínez Zuviría. En los tres casos se trata de autores fuertemente identificados con rosismo. 


\section{Leer a Blomberg}

Quien se refirió al vínculo de Blomberg con la figura de Rosas, fue Manuel Gálvez. Con cierta sorna relató en sus memorias que a fines de 1946 había recibido tres extensas cartas suyas en las que le contó que escribiría una novela titulada La gesta de Juan Sin Ropa cuyo protagonista sería "la plebe argentina". La cual empezaría con "los emponchados de las invasiones inglesas" y llegaría hasta "los descamisados de hoy". A lo que le agregó que el mismo Gálvez aparecería en dicha novela "como nuestro novelista y escritor máximo". Por tal razón le solicitó, le respondiera una serie de preguntas, de las cuales Gálvez recordaba particularmente una: “¿Qué estadista o político argentino, aparte de Rosas e Hipólito Yrigoyen, comprendió claramente los anhelos instintivos de la masa popular a lo largo de nuestra historia y por qué la idea socialista nunca arraigó en aquélla?". En ese sentido agregó: "Esto parece demostrar que Blomberg, antirrosista, hubiese cambiado de opinión. Aunque creo que el autor de varias novelitas sobre la época de don Juan Manuel debía sentir una secreta simpatía por la figura del Restaurador" (Gálvez, 2003:637).

En cierta consonancia con la afirmación anterior, vale traer aquí un comentario aparecido en el correo de lectores del Boletín de Instituto de Investigaciones Históricas Juan Manuel de Rosas (de aquí en más BIIHJMR) en 1951, donde un "Curioso" - a secas- de Capilla del Señor afirmó: "No lo sabemos a ciencia cierta, pero aunque no fuera más que por el jugo que le ha sacado a Rosas y a su época, Héctor Pedro Blomberg debiera ser rosista". ${ }^{16}$

Por otro lado, en 1943 el escritor Conrado Nalé Roxlo incluyó a Blomberg dentro de su Antología apócrifa, que consistió en una serie de "ejercicios literarios" que, afirmó, "podrían ser la historia de mis simpatías y diferencias" dedicado a "los maestros admirados que en él figuran" (Nalé Roxlo, 1943: 7). Allí incluyó Siesta de Palermo donde ironizó "A la manera de Héctor Pedro Blomberg". Esta intervención fue recogida diez años después por el BIIHJMR para apuntar, desde allí, contra "esas ya verdaderamente inefables composiciones del vate Héctor Pedro Blomberg". A lo que se agregó, "a quien personalmente profesamos todo el respeto que se merece por sus dotes de escritor, terminó por caer en la repetición del lugar común". A saber: "seguir manteniendo todo ese clima falso de puñales y de sangre, de arbitrariedad y terror con que se pretende signar de modo principal, casi absoluto, la época del gobierno de Don Juan Manuel de Rosas". En otro pasaje de la misma se afirmó que el "antirrosismo" de Blomberg se expresa en su "interesante recopilación poética de aquel momento argentino", que fue su Cancionero federal de 1934,

16 “Correo revisionista”, BIIHJMR núm. 4, año IV, febrero de 1951, p. 15 
donde "estampó [...] juicios que en lo esencial se corresponden con el ambiente y el clima de sus propias composiciones en verso sobre el tema". ${ }^{17}$

Es interesante resaltar que esta posición es distinta a una asentada en el mismo BIIHJMR en 1969, cuando Luis Soler Cañas reconoció a la lírica de Blomberg en un artículo titulado "La literatura de Vuelta de Obligado" (Soler Cañas, 1969: 15-18). Este mismo autor había publicado con anterioridad un artículo en la revista Jauja, dirigida por el padre Leonardo Castellani, titulado "Imágenes de Juan Manuel de Rosas en la Poesía del Siglo XX". Allí, polemizó con Nalé Roxlo sobre la valoración de la obra de Blomberg, y afirmó:

"Cabe consignar, con justicia para Blomberg, chivo emisario en el caso, que aunque éste enfocó con demasiada frecuencia, quizás, los temas rosistas, se mantuvo siempre, tanto en sus novelizaciones dramáticas para la radiofonía como en sus letrillas de canciones populares en un nivel de decoro y de mesura. Pero fue Blomberg quien puso en boga el tema de Rosas en determinado momento y al punto surgieron numerosos imitadores que distaban de poseer su gusto y su discreción. Por eso creo, volviendo sobre un relativamente viejo juicio mío al respectó, que Nalé Roxlo centra en el autor de Las puertas de Babel defectos que en rigor pertenecen a sus imitadores o tendencias exageradas en las que incurrían incluso poetas de más levantado vuelo que éstos, como Mujica Láinez, arraigados en una concepción que estaba -y está- más hundida en su sangre que en su razonar" (Soler Cañas, 1968: 13).

Diez años antes, en 1958, este mismo autor había puesto en valor el ya citado Cancionero federal publicado por Blomberg en 1934, al ponerlo en dialogo con su propio trabajo sobre "el cancionero de la federación" publicado por el IIHJMR (Soler Cañas, 1958) ${ }^{18}$. Si bien los elementos para sacar conclusiones son dispersos, sostenemos que alcanzan para afirmar que la posición del revisionismo rosista con respecto a la obra de este autor ha tenido lecturas heterogéneas, ha sido ambivalente $\mathrm{o}$, al menos, cambiante.

Una hipótesis potente es que el reconocimiento de matices positivos respecto de su obra podría corresponderse con los momentos en los que el revisionismo rosista ganó tenor y masividad. Lo que es seguro es que el hecho de que estas deliberaciones aún se encuentren en curso para los años cincuenta

\footnotetext{
17 "Una fina cachada a la cursilería de Blomberg", BIIHJMR núm. 16 año V, Buenos Aires, diciembre de 1952, p. 10

${ }^{18}$ Allí el autor repasó una serie de obras que se vieron influenciadas por el trabajo de Blomberg: Candombe, de Bernardo Kordon; Morenada y Cancionero del tiempo de Rosas de José Luis Lanuza, Mapa de la poesía negra americana de Emilio Ballagas; Negros y morenos en el cancionero rioplatense de Horacio Jorge Becco (Soler Cañas, 1958:34).
} 
y sesenta, sumado al modo respetuoso en que se refieren a su obra, da cuenta sobre todo- de la pregnancia de la obra de este autor.

Por último cabe incluir en este derrotero, las versiones de dos obras de Blomberg y Maciel, en Canción para mi patria joven grabado por Roberto Rimoldi Fraga en 1971. No solo es sugestiva la connotación que estas interpretaciones pueden haberle impreso a aquellas composiciones, debido a la fuerte identificación de esta figura con el rosismo en aquel momento. Sino también porque se dieron en su momento de mayor popularidad.

\section{Conclusiones}

A lo largo de este trabajo hemos intentado reconstruir el lugar de enunciación de Blomberg en lo que hace a su producción de representaciones de temática rosista, y las imágenes que este puso en circulación. De esa manera intentamos, no solo ponderar su obra, sino también auscultar algunos elementos vinculados a sus condiciones de producción. Así buscamos mostrar algunas características centrales de las representaciones producidas por este, así como las diferencias o puntos de contacto, con relación a la historiografía revisionista.

A los fines de caracterizar ambos casos, pero con el cuidado de no abordarlos como compartimentos estancos, nos dimos la tarea de exponer cuáles fueron algunas de esas representaciones en concreto. De esa manera identificamos, para el caso del revisionismo rosista, un encadenamiento de sentidos vinculado a la figura de Rosas bajo los tópicos del criollismo, el antiliberalismo, el hispanismo católico y el antiimperialismo. Mientras que para el caso de Blomberg trabajamos en un registro distinto, donde la textura de la narrativa siempre estuvo diagramada fundamentalmente sobre los fenómenos de la cultura popular de aquel tiempo. De cualquier manera es interesante ver el modo en que Blomberg consumió literatura revisionista para poder pensar sus escenarios. De la misma manera que Soler Cañas parece haberlo hecho con su obra, para poder reconstruir los fragmentos del cancionero popular rosista. Tal como lo enfatizó Sylvia Saítta, y también nosotros aquí, todo ello sucedió en simultáneo.

Otro elemento importante para subrayar, es el modo en que la estética criollista atravesó a uno y otro ámbito de producción de representaciones. Si bien en cada caso tamizado por elementos distintos, su concordancia da cuenta de la manera en que Rosas, su época y el criollismo, se amalgamaron de manera tal que reforzaron -al mismo tiempo que parecieran haber sido fruto de- una tradición de peso en los imaginarios nacionales: aquella que Cattaruzza definió como "la nación del gaucho".

Es interesante traer aquí una anécdota de Adolfo Bioy Casares, quien recordó en sus memorias una conversación -en junio de 1969-, cuando él 
mismo le afirmó a Jorge Luis Borges, refiriéndose a Eduardo Gutiérrez, los hermanos Podestá y José Hernández, que "Entre todos ellos han mantenido vivo cuánto hay de peor en el país; Hernández extrañaba a Rosas y preparaba el peronismo" (Bioy Casares, 2006:1097). Nadie podría dudar de la aversión de Gutiérrez por Rosas, menos aún de la aversión Bioy Casares y Borges por aquel y por Juan Domingo Perón. Pero en los entretelones de la anécdota se esconde el problema. No es sencillamente el contenido lo que demarcó, de una vez y para siempre el sentido del enunciado, sino que algo también hay en su persistencia. Aquellos "ecos" y "resonancias" a las cuales se refirió Smith. Aquella "permanencia del tema" al que se refirió Prieto. Si la figura de Rosas tomó una carnadura fantasmagórica en los imaginarios nacionales de aquellos años, sin duda la obra de Blomberg se cuenta entre las que, intencionalmente o no, lo alimentaron.

No queremos decir aquí que Blomberg haya sido rosista. Más aún, si a los datos fácticos nos referimos, sus declaraciones documentadas dejaron asentado lo contrario. Pero se trata de una sutileza distinta. Se trata de saber si aquellas imágenes, por su fuerza estética, por su popularidad y por los materiales que utilizó para confeccionarlas, no pueden haber sido lo suficientemente maleables para ser reintroducidas en una tradición política que -como todas-, en su propio proceso de actualización a distintas coyunturas, supo alimentarse de enunciados, imágenes y demás elementos con fuerte pregnancia social.

Por último, creemos que es posible ver a partir de los elementos vertidos en este trabajo, la manera en la cual el primer revisionismo rosista fue eficaz en construir su propia "voz" en el debate historiográfico con la tradición liberal. Así generó las condiciones para que todos los enunciados circulantes en torno a Rosas, se licuaran en una lectura maniquea. Podemos decir que el revisionismo guardó silencio primero, ante las representaciones de Rosas -y su época producidas por Blomberg, las aplastó después - apoyándonos en Macor -, pero también supo integrarlas a la tradición reivindicativa rosista cuando lo encontró propicio.

\section{Bibliografía citada}

Adamovsky, Ezequiel (2019). El gaucho indómito: de Martín Fierro a Perón, el emblema imposible de una nación desgarrada. Buenos Aires, Argentina: Siglo XXI.

Bajtín, Mijaíl (2002). Estética de la creación verbal. Buenos Aires: Siglo XXI.

Berman, Mónica (2018). La construcción de un género radiofónico: el radioteatro. Buenos Aires: EUDEBA.

Blomberg, Héctor P. (1928) "La sangre de las guitarras", La mejor novela, año 1, núm. 15. 
Blomberg, Héctor P. (1932). La mulata del restaurador: novela histórica. Buenos Aires: Atlántida.

Blomberg, Héctor P (1933). La cantora de la Merced. Buenos Aires: Anaconda.

Blomberg, Héctor P. (1936). Cancionero federal. Buenos Aires: Ediciones Anaconda.

Blomberg, Héctor P. (1936). Canciones históricas. Buenos Aires: TOR.

Blomberg, Héctor P. y Viale Paz, Carlos Max (1930). “La pulpera de Santa Lucía", La Escena núm. 648.

Blomberg, Héctor P. y Viale Paz, Carlos Max (1932). "La mulata del Restaurador", Revista teatral Bambalinas nº 732 Año XIV.

Cattaruzza, Alejandro (2003). "El revisionismo: itinerarios de cuatro décadas", en: Alejandro Cattaruzza y Alejandro Eujanian, Políticas de la historia. Argentina 1860-1960. Buenos Aires: Alianza editores, pp. 143-182

Cattaruzza, Alejandro (2007). Los usos del pasado. Buenos Aires: Sudamericana.

Cattaruzza, Alejandro (2017). “El pasado como problema político", Anuario IEHS, no 32 , pp.59-78

Corvalán Mendilaharsu, Dardo (1929). Rosas .Buenos Aires: M. Gleizer Editor.

Devoto, Fernando y Pagano, Nora (2009). Historia de la historiografía argentina. Buenos Aires: Sudestada.

Fradkin, Raúl y Gelman, Jorge (2016). Juan Manuel de Rosas. La construcción de un liderazgo político. Buenos Aires: Edhasa.

Gálvez, Manuel [1940] (2007). Vida de Juan Manuel de Rosas. Buenos Aires: Claridad.

Gálvez, Manuel [1961] (2003). Recuerdos de la vida literaria II. Entre la novela y la historia. En el mundo de los seres reales. Buenos Aires: Taurus.

Goebel. Michael (2013). La Argentina partida: Nacionalismos y políticas de la historia. Buenos Aires: Prometeo.

Ibarguren, Carlos [1930] (1997). Juan Manuel de Rosas. Su vida, su drama, su tiempo. Buenos Aires: THEORÍA.

Irazusta, Julio (1935). Ensayo sobre Rosas .Buenos Aires: Editorial TOR.

Karush, Matthew B. (2013). Cultura de clase. Radio y cine en la creación de una Argentina dividida (1920-1946) .Buenos Aires: Ariel.

Macor, Darío (1995). “Imágenes de los años treinta. La invención de la década del treinta en el debate político intelectual de la Argentina sesentista", Documento de Trabajo no 3, Programa de Estudios Interdisciplinarios de Historia Social. Santa Fe: Universidad Nacional del Litoral. 
Maranghello, Cesar (2016). Eva Duarte, más allá de tanta pena .Buenos Aires: EUDEBA/Proteatro.

Nalé Roxlo, Conrado (1943). Antología apócrifa .Buenos Aires: Hachette.

Navarro Gerassi, Marysa (1968). Los nacionalistas. Buenos Aires: Jorge Álvarez.

Prieto, Adolfo (1959). Proyección del rosismo en la literatura argentina. Rosario: Universidad Nacional del Litoral.

Prieto, Adolfo (2006). El discurso criollista en la formación de la Argentina moderna. Buenos Aires: Sudamericana.

Quattrocchi Woisson, Diana (1995). Los males de la memoria. Historia y política en la Argentina. Buenos Aires: Emecé.

Rea, Lauren (2013). Argentine Serialised Radio Drama in the Infamous Decade, 19301943: Transmitting Nationhood .Farnham: Ashgate.

Romano, Eduardo (1985). “¿Existió el “escritor” de radioteatro?”, en: Aníbal Ford, Jorge Rivera y Eduardo Romano. Medios de comunicación y cultura popular .Buenos Aires: Legasa, pp. 53-64

Saítta, Silvya (2013). Regueros de tinta. El diario Crítica en la década de 1920 .Buenos Aires, Siglo XXI.

Saítta, Silvya (2019). "Los usos de la historia en los comienzos de la radio argentina". Revista Latinoamericana de Ciencias de la Comunicación, nº18 (vol. 32), pp. 326-337.

Schaffer Gallo, Carlos (1931). “La mazorquera de Monserrat", en: La Escena no 659, Año XIV.

Smith, A. (2009). Ethno-Symbolism and Nationalism. A Cultural Approach. New York: Routledge.

Soler Cañas, Luis (1958). Negros gauchos y compadres: en el cancionero de la federación .Buenos Aires: Instituto de Investigaciones Históricas Juan Manuel de Rosas.

Soler Cañas, Luis (1968). “Imágenes de Juan Manuel de Rosas en la Poesía del Siglo XX", Revista "Jauja" núm. 18, pp.8-14.

Soler Cañas, Luis (1969). “La literatura de Vuelta de Obligado”, BIIHJMR, núm. 4 Año II, pp. 15-18.

Viñas, David [1964] (1982). Literatura argentina y realidad política. Buenos Aires: Centro Editor de América Latina. 